\title{
PENGARUH PEMBERIAN SELF HYPNOSIS TERHADAP PEMENUHAN KEBUTUHAN TIDUR PADA LANSIA DI LINGKUNGAN GEDUR BARU MATARAM
}

\author{
I Made Eka Santosa* \\ *Dosen Sekolah Tinggi Ilmu Kesehatan (STIKES) Mataram \\ Email: imadeekasantosa@gmail.com
}

\begin{abstract}
ABSTRAK
Usia lanjut adalah faktor yang paling sering berhubungan dengan peningkatan prevalensi gangguan tidur. Tingginya masalah pemenuhan kebutuhan tidur yang terjadi pada lansia memerlukan penanganan yang sesuai untuk meningkatkan pemenuhan kebutuhan tidur. Gangguan tidur dimanifestasikan dengan perasaan lelah, gelisah, palpebra nampak hitam, kelopak mata bengkak, konjungtiva merah, sakit kepala dan sering menguap dan mengantuk. Kualitas tidur sangat penting bagi kesehatan lansia secara umum.

Salah satu tindakan non farmakologis yang dapat meningkatkan pemenuhan kebutuhan tidur pada lansia adalah dengan melakukan self Hypnosis. Self hypnosis merupakan bagian dari hypnotherapy yang menekankan pada penggunaan kalimatkalimat sugesti yang memberikan efek menenangkan dan relaksasi maksimal otot-otot tubuh sehingga memudahkan lansia untuk tidur. Penelitian ini bertujuan untuk mengetahui pengaruh self hypnosis terhadap pemenuhan kebutuhan tidur pada lansia di Lingkungan Gedur Baru Mataram

Desain penelitian yang digunakan pada penelitian ini adalah disain pra eksperimental dengan menggunakan rancangan one group pretest-posttest design. Sampel penelitian ini adalah lansia yang mengalami gangguan pemenuhan kebutuhan tidur yang berjumlah 33 lansia dengan menggunakan Total Sampling. Analisa data dilakukan dengan Uji Paired T-Test. Berdasarkan uji statistik diperoleh nilai $\mathrm{p}=0,000$ $>$ Alfa $=0,05$ maka dapat disimpulkan bahwa ada pengaruh self hypnosis terhadap pemenuhan kebutuhan tidur pada lansia sehingga dapat direkomendasikan sebagai salah satu intervensi keperawatan mandiri untuk membantu lansia yang mengalami gangguan pemenuhan kebutuhan tidur.
\end{abstract}

Kata Kunci: Self hypnosis, kebutuhan tidur, lansia

\section{PENDAHULUAN}

Usia lanjut adalah faktor yang paling sering berhubungan dengan peningkatan prevalensi gangguan tidur. Fenomena yang sering dikeluhkan lansia daripada usia dewasa muda adalah : gangguan tidur, ngantuk siang hari, tidur sejenak di siang hari. Sementara itu seorang lansia dikatakan terpenuhi kebutuhan tidurnya dengan melihat pada parameter kualitas tidur seperti lamanya tidur, waktu yang diperlukan untuk tidur, frekuensi terbangun, dan beberapa aspek subjektif seperti kedalaman tidur, perasaan segar di pagi hari, kepuasaan tidur, serta perasaan lelah siang hari (Bukit, 2003). Ketika parameter tersebut tidak terpenuhi maka dapat dimaknai bahwa lansia mengalami masalah pemenuhan kebutuhan tidur. Masalah ini cukup umum terjadi pada lansia terkait dengan perubahan fisiologis karena proses menua.

Disamping perubahan sistem regulasi dan fisiologis, penyebab 
gangguan tidur primer pada lansia adalah insomnia. Selain itu gangguan mental lain, kondisi medis umum, faktor sosial dan lingkungan. Gangguan tersering pada lansia pria adalah gangguan rapid eye movement (REM). Hal yang menyebabkan gangguan tidur juga termasuk adanya gejala nyeri, nokturia, sesak napas, nyeri perut. Keluhan utama pada lansia sebenarnya adalah lebih banyak terbangun pada dini hari dibandingkan dengan gangguan dalam tidur (Guyton, 2003). Perburukan yang terjadi adalah perubahan waktu dan konsolidasi yang menyebabkan gangguan pada kualitas tidur pada lansia.

Tingginya masalah pemenuhan kebutuhan tidur yang terjadi pada lansia memerlukan penanganan yang sesuai untuk meningkatkan pemenuhan kebutuhan tidur. Kualitas tidur sangat penting bagi kesehatan lansia secara umum. Pemenuhan kebutuhan tidur setiap individu lansia berbeda-beda dan terlihat dari kualitas tidurnya (Nugroho, 2008). Kebutuhan kualitas tidur ada yang terpenuhi dengan baik dan ada yang mengalami gangguan.

Gangguan tidur secara umum merupakan suatu keadaan dimana individu mengalami atau mempunyai resiko dalam kualitas tidur yang menyebabkan ketidaknyamanan. Gangguan tidur dimanifestasikan dengan perasaan lelah, gelisah, palpebra nampak hitam, kelopak mata bengkak, konjungtiva merah, sakit kepala dan sering menguap dan mengantuk (Smeltzer \& Bare, 2002)

Gangguan tidur ini terjadi pula pada lansia di Lingkungan Gedur Baru Mataram. Jumlah lansia di Lingkungan Gedur Baru Mataram pada bulan September 2019 sebanyak 48 lansia. Setelah dilakukan pengkajian didapatkan data sebanyak 33 lansia yang mengalami gangguan tidur.

Agar terpenuhinya kebutuhan tidur pada lansia diperlukan suatu upaya berupa terapi farmakologis dan non farmakologis. Terapi farmakologis terkait dengan penggunaan obat-obatan untuk memicu lansia tertidur yang pada dosis tertentu atau salah dapat mengakibatkan efek samping yang tidak baik bagi tubuh lansia terutama ginjal (Purwanto, 2007). Terapi farmaologis hanya digunakan pada kondisi yang memang benar-benar membutuhkan. Terapi yang dianjurkan adalah non-farmakologis dengan beberapa modalitas seperti herbal-remedies, tehnik distraksi dan relaksasi, pengaturan konsumsi makanan termasuk salah satu diantaranya yaitu Self Hypnosis.

Terapi self hypnosis dapat diartikan sebagai tindakan memberikan sugesti kepada diri sendiri melalui kalimatkalimat sugestif yang telah disusun dan direkam berdasarkan permasalahan pasien serta tingkat pemahaman pasien. Self hypnosis adalah modalitas therapi dimana pasien mendengarkan suara therapis atau suaranya sendiri Terapi ini mudah untuk dilakukan oleh lansia dan tidak mempunyai efek samping yang berbahaya bagi tubuh lansia sehingga layak menjadi modalitas pemenuhan kebutuhan tidur lansia.

Self hypnosis merupakan bagian dari hypnotherapy yang menekankan pada penggunaan kalimat-kalimat sugesti yang memberikan efek menenangkan dan relaksasi maksimal otot-otot tubuh (International Journal of Clinical and Experimental Hypnosis, 2000) Dalam prosesnya, self hypnosis mendorong pasien untuk mengatur pernafasan menjadi lebih dalam sehingga secara fisiologis akan meningkatkan masuknya oksigen kedalam paru dan paru akan lebih mudah mendistribusikan ke dalam sel. Kondisi ini menyebabkan relaksasi total pada sel-sel tubuh baik otot maupun otak. Dalam kondisi tenang dan relaksasi maka lebih mudah bagi lansia untuk memenuhi kebutuhan tidurnya secara mandiri (Smith, 2011)

\begin{tabular}{llrr}
\multicolumn{2}{r}{ Pada pelaksanaan } & self & hypnosis, \\
terapis membantu & klien & untuk \\
memecahkan masalah & mereka & sendiri
\end{tabular}


dengan menuangkannya dalam bentuk script atau naskah yang akan dibaca dan direkam. Dengan demikian self hypnosis dapat bersifat sangat individual. Sebagai awal, terapis dapat memberikan instruksi sederhana tentang bagaimana mempelajari self hypnosis dan membuat sebuah naskah self hypnosis yang dapat di rekam untuk klien sendiri. Intinya bahwa setelah melakukan wawancara dengan pasien, terapis akan membuat konsep naskah yang akan dibaca dan direkam oleh terapis atau oleh pasien itu sendiri. Script self hypnosis awalnya dibuat oleh terapis, kemudian dapat dibuat oleh lansia sendiri setelah diajarkan oleh terapis. Hasil rekaman suara dari naskah tersebut kemudian diperdengarkan kepada lansia sebagai bentuk modalitas therapi pemenuhan kebutuhan tidur. Penelitian ini bertujuan untuk mengetahui pengaruh pemberian Self Hypnosis terhadapa kebutuhan tidur lansia pada lansia di lingkungan Gedur baru Mataram.

\section{A. METODOLOGI}

\section{Populasi, Sampel dan Tehnik Sampling}

Populasi dalam penelitian ini adalah Lansia yang mengalami gangguan pemenuhan kebutuhan tidur di Lingkungan Gedur Baru, Kelurahan Abiantubuh, Kecamatan Cakranegara Selatan, Kota Mataram, Propinsi Nusa Tenggara Barat. Tehnik sampling yang digunakan adalah total sampling sehingga sampel dalam penelitian ini adalah lansia yang mengalami gangguan pemenuhan kebutuhan tidur yang berjumlah 33 lansia.

\section{Rancangan Penelitian}

Desain yang digunakan dalam penelitian ini adalah preeksperimental design dengan jenis rancangan menggunakan one group pretest-posttest design (Sugiyono, 2010)

\section{Instrumen Penelitian}

Instrumen yang digunakan dalam penelitian ini adalah lembar observasi pemenuhan kebutuhan tidur dan kuisioner tentang kualitas tidur lansia.

\section{Variabel}

Variabel independen dalam penelitian ini adalah Teknik Self Hypnosis yaitu mendengarkan rekaman suara dari kalimatkalimat sugestif yang telah disusun sebelumnya. Rekaman suara mencakup tahapan-tahapan proses hypnosis dari pre-induksi, induksi, depth level test, post hypnotic suggestion, dan terminasi.

Variabel dependen dalam penelitian ini adalah pemenuhan kebutuhan tidur yaitu terpenuhinya kualitas tidur pasien sesuai dengan kebutuhan tidur yang terlihat dari terpenuhinya parameter kualitas tidur, seperti lamanya tidur, waktu yang diperlukan untuk tidur, frekuensi terbangun dan beberapa aspek subjektif, seperti kedalaman tidur, perasaan segar di pagi hari, kepuasan tidur serta perasaan lelah siang hari

\section{Analisa Data}

Untuk menganalisis pengaruh antara kedua variabel maka dilakukan uji statistik dengan $T$ Paired Test pada tingkat kepercayaan $95 \% \quad(\alpha=0.05)$ dengan bantuan program SPSS untuk mengetahui adanya perbedaan sebelum dan sesudah di berikan perlakuan.

\section{B. Hasil Penelitian}

Penelitian ini dilakukan di Lingkungan Gedur Baru Mataram pada bulan September 2019. Sebelum perlakuan dilakukan pengukuran terhadap pemenuhan kebutuhan tidur lansia menggunakan kuesioner dan 
lembar observasi pemenuhan kebutuhan tidur. Kemudian pemberian self hypnosis pada lansia yang mengalami gangguan pemenuhan kebutuhan tidur dilaksanakan setiap hari sebanyak satu kali selama dua minggu.

Setelah pemberian perlakuan selama dua minggu selesai, peneliti melakukan post test untuk mengevaluasi sejauh mana perkembangan responden setelah diberikan perlakuan. Berikut adalah hasil penelitian pemenuhan kebutuhan tidur sebelum dan sesudah perlakuan self hypnosis pada 33 lansia yang berusia 60 tahun keatas di Lingkungan Gedur Baru Mataram.

\section{Karakteristik Responden}

Tabel 1.1. Karakteristik responden berdasarkan jenis kelamin

\begin{tabular}{|l|l|l|l|}
\hline No & Jenis Kelamin & F & \% \\
\hline 1 & Laki-Laki & 17 & $51,5 \%$ \\
\hline 2 & Perempuan & 16 & $48,5 \%$ \\
\hline & Jumlah & 33 & $100 \%$ \\
\hline
\end{tabular}

2. Analisis pemenuhan kebutuhan tidur lansia sebelum Self Hypnosis dan sesudah Self Hypnosis

Tabel 1.2. Analisis pemenuhan kebutuhan tidur pada lansia sebelum dan sesudah dilakukan Self Hypnosis.

\begin{tabular}{|c|c|c|c|c|c|c|}
\hline \multirow[t]{2}{*}{ No } & \multirow{2}{*}{$\begin{array}{l}\text { Kebutuhan } \\
\text { tidur lansia }\end{array}$} & \multicolumn{2}{|c|}{ Sebelum } & \multicolumn{2}{|c|}{ Sesudah } & \multirow{2}{*}{$\begin{array}{l}\text { T-Test } \\
\mathrm{P}=\end{array}$} \\
\hline & & $\mathrm{f}$ & $\%$ & f & $\%$ & \\
\hline 1 & $\begin{array}{l}\text { Tidak } \\
\text { Terpenuhi }\end{array}$ & 0 & $0 \%$ & 4 & $12 \%$ & 0,000 \\
\hline 2 & Terpenuhi & 33 & $100 \%$ & 29 & $88 \%$ & \\
\hline & Jumlah & 33 & $100 \%$ & 33 & $100 \%$ & \\
\hline
\end{tabular}

\section{PEMBAHASAN}

1. Pemenuhan kebutuhan tidur pada lansia sebelum dilakukan self hypnosis

Tabel 1.1. menunjukkan bahwa semua lansia yang menjadi responden pada penelitian ini mengalami kondisi tidak terpenuhinya kebutuhan tidur lansia. Hal ini sesuai dengan kriteria sampel yaitu lansia yang mengalami gangguan pemenuhan kebutuhan tidur. Gangguan pemenuhan kebutuhan tidur yang didapatkan dari observasi dan pengisian kuesioner berupa kesulitan untuk memulai tidur, sering terbangun di malam hari, kesulitan untuk tidur kembali adanya pengganggu tidur berupa nyeri.

Tidur merupakan kebutuhan dasar yang melibatkan pengalaman subyektif. Hanya individu itu sendiri yang dapat melaporkan apakah tidur cukup atau tidak (Lumbantobing, 2004) Dengan demikian data dari kuesioner sangatlah penting. Namun gangguan istirahat tidur dapat pula diamati berupa kehilangan konsentrasi, sering menguap, mata tampak kemerahan dan terlihat lesu (Potter \& Perry, 2005). Manifestasi ini dapat diamati dengan observasi kepada pasien lansia.

Rata-rata normal kebutuhan tidur pada lansia berkisar antara 56 jam sehari, namun dapat bervariasi. Individu yang berusia 60 tahun ke atas (katagori usia lansia) yang sehat membutuhkan tidur untuk dapat tetap berpartisipasi dalam mengisi aktivitas sehari-hari mereka (Muhtar \& Haris, 2007). Akan tetapi proses menua dapat menyebabkna kemunduran fisik dan psikologis secara bertahap. Kemunduran tersebut dapat menyebabkan berbagai masalah, salah satunya adalah gangguan pemenuhan kebutuhan tidur yang sering terjadi pada lansia (Hardywinoto \& Setiabudi, 2009) 
Seiring perubahan usia, tanpa disadari pada orang lanjut usia akan mengalami perubahanperubahan fisik, psikososial dan spiritual. Salah satu perubahan tersebut adalah perubahan pemenuhan kebutuhan tidur. Hal ini terjadi karena menurunnya fungsi dari system-sistem organ tubuh untuk melaksanakan fungsinya secara maksimal, serta menurunnya aktivitas sehari-hari yang merupakan beberapa faktor yang mengganggu terpenuhinya pemenuhan kebutuhan tidur seseorang (Stanley, 2006)

Berdasarkan teori diatas dan dikaitkan dengan hasil penelitian menunjukan bahwa klien lansia dengan kondisi menurunnya fungsi dari sistem organ tubuh didalam melaksanakan fungsinya secara maksimal akan mengalami gangguan pemenuhan kebutuhan tidur. Gangguan ini dapat berupa kesulitan memulai tidur, gangguan dalam mempertahankan diri untuk tetap tertidur serta gangguan dalam kualitas tidur. Hal ini terjadi sebagai akibat dari proses menua, perubahan status kesehatan, kondisi sakit yang dialami serta perubahan lingkungan (Widastra, 2009).

\section{Pemenuhan kebutuhan tidur pada lansia sesudah dilakukan self hypnosis}

Tabel 1.1 diatas menunjukkan bahwa pemenuhan kebutuhan tidur lansia terpenuhi sesudah dilakukan self hypnosis setiap hari selama dua minggu. Dari 33 responden lansia, hanya 4 responden yang masih mengalami gangguan pemenuhan kebutuhan tidur walapun skor observasi dan kuesioner meningkat. Sementara itu 29 responden kebutuhan tidurnya terpenuhi.

Ada beberapa faktor yang menyebabkan hal ini diantaranya adalah responden tidak mengikuti program self hypnosis secara rutin dan kurang kooperatif dikarenakan penyakit fisik yang menyebabkan ketidaknyamanan fisik. Faktor lainnya adalah adanya lansia yang mengalami stres emosional yang menyebabkan seseorang menjadi tegang dan sering kali mengarah frustasi sehingga sulit untuk tidur. Stres juga menyebabkan seseorang mencoba terlalu keras untuk tertidur, sering terbangun selama siklus tidur. Stres yang berkelanjutan akan menyebabkan kebiasaan tidur yang buruk (Stanley, 2007).

Terpenuhinya kebutuhan tidur pada sebagian besar lansia tersebut setelah diberikan self hypnosis karena dapat menurunkan ketegangan fisiologis, meningkatkan relaksasi otot dan menurunkan kecemasan. Permasalahan fisik dan psikologis dapat dikurangi sehingga dengan sendirinya permasalahan gangguan pemenuhan kebutuhan tidur dapat diatasi karena self hypnosis dapat memberikan rasa rileks baik secara fisik dan psikologis sehingga kebutuhan tidur dapat terpenuhi.

Teknik self hypnosis merupakan bagian dari hypnotherapy yang kegiatan hipnotisnya dipandu oleh terapis namun dilakukan sendiri oleh klien dengan memberikan sugesti terhadap dirinya sendiri untuk mengatasi masalah pikiran, perasaan dan prilaku (Smith, 2011). Mekanismenya diawali dengan wawancara terapis-klien sehingga didapatkan permasalahan yang mengganggu kondisi psikis 
klien. Subjek permasalahan kemudian menjadi bahan penulisan naskah untuk rekaman suara. Naskah berisikan kalimat-kalimat sugestif yang menekankan pada pemecahan masalah klien. Naskah dapat dibaca oleh terapis atau klien sendiri. Setelah proses rekaman selesai kemudian hasil rekaman diperdengarkan kepada klien setiap hari. Rekaman suara ini akan memberikan efek menenangkan bagi pasien. Proses ini bisa dipersingkat dengan memperdengarkan rekaman suara terapis yang mencakup sugesti yang bersifat umum dipahami oleh setiap klien.

Pemberian self hypnosis termasuk didalamnya adalah proses pengaturan pernafasan dapat menurunkan ketegangan fisik, meningkatkan relaksasi otot, dan menurunkan kecemasan sehingga terjadi vasodilatasi pembuluh darah. Aliran darah sistemik menjadi lancar, denyut nadi menjadi normal, frekuensi pernapasan menjadi normal, dan mengurangi evaporasi sehingga menjadi nyaman dan pikiran menjadi tenang. Responden merasakan mudah untuk memulai tidur, frekuensi terbangun di malam hari menurun, perasaan lebih segar saat terbangun, merasa lebih puas dengan tidur yang dialami, tidur dengan nyenyak serta merasa kuat saat beraktivitas pada siang hari.

\section{Kesimpulan}

1. Sebelum diberikan self hypnosis pada responden seluruh responden mengalami gangguan pemenuhan kebutuhan tidur. Setelah diberian self hypnosis 29 responden (88\%) terpenuhi kebutuhan tidurnya dan
4 responden (12\%) belum terpenuhi kebutuhan tidurnya.

2. Setelah dilakukan Uji T-Paired Test didapatkan nilai $\mathrm{p}=0,000<$ dari Alfa 0,05 sehingga dapat disimpulkan ada pengaruh pemberian self hypnosis pada responden lansia di Lingkungan Gedur Baru Mataram. 


\section{DAFTAR PUSTAKA}

Bukit, E.L. 2003. Thesis : sleep quality and factors interfering with sleep among hospitalized elderly in medical units Medan Indonesia. Prince of Songkla University

Guyton, A.C \& Hall. 1997. Buku Ajar Fisiologi Kedokteran. Jakarta: EGC

Hardywinoto, D \& Setiabudhi, T (1999). Panduan Gerontologi Tinjauan dari Berbagai Aspek. Jakarta: PT Gramedia Pustaka Utama

International Journal of Clinical and Experimental Hypnosis Vol. 48, No 2. 2000. http:// ijceh. com/ content/ view/169/81/

Lumbantobing. 2004. Gangguan Tidur. Jakarta: Balai Penerbit FK-UI.

Muhtar \& Haris, A. 2010. Pengaruh relaksasi otot progresif terhadap pemenuhan kebutuhan istirahat tidur klien di Ruangan VIP-B RSUD Bima.

Nugroho, W.2008. Keperawatan Gerontik \& geriatric Edisi 3. Jakarta : EGC.

Potter \& Perry. 2005. Buku Ajar Fundamental Keperawatan. Jakarata : EGC

Purwanto, S. 2007. Efektifitas Terapi Relaksasi Religius dalam mengurangi gangguan insomnia di Universitas Muhammadiyah Surakarta. Diambil tanggan 9 Desember 2015

Smeltzer \& Bare. 2002. Fundamental Of Nursing, Addison-Wesley Publishing Company,California

Smith, B.L. 2011. Hypnosis Today. American Psychological Association. Monitor on Psychology. January 2011, Vol 42, No. 1

Sugiyono. 2010. Statistic Untuk Penelitian. Bandung :Alfabeta.

Stanley, M. 2007. Buku Ajar Keperawatan Gerontik. Jakarta : EGC

Widastra, I. M. 2009. Terapi Relaksasi Otot Progresif Sangat Efektif
Mengatasi Keluhan Insomnia pada Lansia. Gempar :Jurnal Ilmiah Keperawatan No.2 Vol.1, 84-89. September $\quad 12, \quad 2011$. http://isjd.pdii.lipi.go.id 